STUDI

FRANCESI

\section{Studi Francesi}

Rivista quadrimestrale fondata da Franco Simone

190 (LXIV | I) | 2020

Varia - fasc. I - gennaio-aprile 2020

\title{
BUATA MALELA, Aimé Césaire et la relecture de la colonialité du pouvoir avec Sartre, Fanon, Glissant, Kourouma, Badian, Schwarz-Bart, Dadié et Ouologuem
}

\section{Elena Fermi}

\section{(2) OpenEdition}

Journals

\section{Édition électronique}

URL : https://journals.openedition.org/studifrancesi/23334

DOI : $10.4000 /$ studifrancesi.23334

ISSN : 2421-5856

Éditeur

Rosenberg \& Sellier

\section{Édition imprimée}

Date de publication : 1 avril 2020

Pagination : 230-231

ISSN : 0039-2944

\section{Référence électronique}

Elena Fermi, « BUATA MALELA, Aimé Césaire et la relecture de la colonialité du pouvoir avec Sartre, Fanon, Glissant, Kourouma, Badian, Schwarz-Bart, Dadié et Ouologuem », Studi Francesi [En ligne], 190 (LXIV | I) | 2020, mis en ligne le 01 mai 2020, consulté le 02 août 2021. URL : http://journals.openedition.org/ studifrancesi/23334; DOI : https://doi.org/10.4000/studifrancesi.23334

Ce document a été généré automatiquement le 2 août 2021.

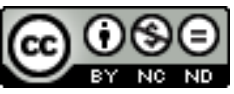

Studi Francesi è distribuita con Licenza Creative Commons Attribuzione - Non commerciale - Non opere derivate 4.0 Internazionale. 


\title{
BuATA MALELA, Aimé Césaire et la relecture de la colonialité du pouvoir avec Sartre, Fanon, Glissant, Kourouma, Badian, Schwarz-Bart, Dadié et Ouologuem
}

\author{
Elena Fermi
}

\section{RÉFÉRENCE}

BUATA MALELA, Aimé Césaire et la relecture de la colonialité du pouvoir avec Sartre, Fanon, Glissant, Kourouma, Badian, Schwarz-Bart, Dadié et Ouologuem, Clamecy, Anibwe éditions, $2019,320 \mathrm{pp}$.

Le volume que nous présentons est une version revue et corrigée par l'auteur de l'édition de 2009, parue sous le titre d'Aimé Césaire. Le fil et la trame. Critique et figuration de la colonialité du pouvoir. Comme Jean Bessière le dit dans sa préface à l'ouvrage, «l'auteur y propose une mise en situation des écrivains antillais et africains ayant dominé la scène littéraire francophone depuis la Seconde Guerre mondiale et une relecture de leurs œuvres» (p. 9). La posture de Malela relève de la sociologie de la littérature: il analyse la production littéraire de ces auteurs «au regard des faits du pouvoir colonial et de l'aliénation» (p. 9), qu'il associe à l'histoire littéraire et à l'histoire des idées caractérisant le champ littéraire francophone depuis le deuxième conflit mondial. Il considère que, dans ce contexte, Aimé Césaire émerge comme figure clé pour sa présence constante sur la scène littéraire pendant la période où le débat anticolonialiste rejoint son apogée, ce qui permet de lire son œuvre en mettant en lumière le face-à-face qu'il y a eu entre les écrivains et la colonialité ou l'aprèscolonialité à partir de la fin de la Seconde Guerre. L'essai se divise en deux grandes 
parties: une première, intitulée «Le moment Césaire» et une deuxième portant comme titre «Paradigme Césaire et postmodernité».

Dans la première partie, Malela parcourt l'histoire du débat autour de la redéfinition de l'«identité nationale» remis à l'honneur par la nouvelle génération d'intellectuels qui, ressortissant des colonies et nés entre 1910 et 1915, se sont formés à Paris. En évoquant les figures d'Aimé Césaire et de sa femme Suzanne, mais aussi Léon Gontran Damas et son ouvrage Pigments (1937), il montre à quel point les positions politiques et littéraires des intellectuels qui proviennent des vieilles terres d'esclavage s'opposent à l'assimilationnisme et commencent à interroger leurs rapports de proximité avec euxmêmes et le monde. Dans un panorama intellectuel qui va être dominé, après la Libération, par la figure de Sartre, puis par les intellectuels réunis autour de "Tel Quel", l'auteur met en relief le rôle fondamental joué par les revues. Si l'expérience de "Tropiques" reste significative, les "Temps modernes" dominent la scène avantgardiste parisienne au détriment de la "NRF" et partagent leur visibilité avec "Présence africaine", "Critique" et les "Lettres nouvelles". Malela trace l'histoire de l'évolution du débat autour du rôle de l'intellectuel au cours de ces années en soulignant la perte progressive d'importance de l'idée sartrienne d'engagement en faveur de celle qui prêche une plus grande autonomie de l'art. Il pose ensuite l'accent sur le débat anticolonialiste dans lequel Aimé Césaire émerge, tout comme Senghor, comme une figure de premier plan. L'auteur poursuit son étude en interrogeant la mise en scène, par l'auteur du Cahier d'un retour au pays natal, de figures de proximité lui permettant de reposer autrement la question de l'historicité et de l'historialité dans les productions de la diaspora afro-antillaise: Toussaint Louverture, le roi Christophe, Patrice Lumumba. C'est notamment à travers la mise en scène théâtrale - affirme Malela - que la revendication anticolonialiste émerge plus lucidement chez les auteurs de la diaspora, à la fois chez les représentants de la génération d'avant la guerre et chez ceux qui, comme Glissant, ont commencé leur carrière après le conflit. La tragédie du roi Christophe, Monsieur Toussaint, Une saison au Congo mais aussi Une Tempête, relecture césairienne de la pièce de Shakespeare, constituent autant d'exemples de mise en scène de la colonialité du pouvoir et de célébration de figures de proximité qui alimentent le débat intellectuel. Dans ce contexte Malela n'oublie pas le rôle joué par la figure de Frantz Fanon, avec Peau noire, masques blancs mais surtout avec Les Damnés de la terre qui, préfacés par Sartre, font préconiser à ce dernier l'agonie de l'Europe, la perte de la position dominante de celle-ci dans le discours intellectuel. L'auteur souligne à quel point, à l'époque, le débat était vif, non seulement entre les intellectuels européens et les ressortissants des anciennes colonies mais aussi parmi les anciens colonisés, car les positions à prendre vis-à-vis de cette problématique étaient très différentes les unes des autres. Si les promoteurs de la Négritude, tels Césaire et Senghor, soutenaient une relation qui devait continuer avec l'ancienne métropole, d'autres, tels que Fanon ou Lumumba prônaient plutôt le recours à la violence dans une véritable lutte de libération contre l'oppression coloniale par laquelle ils se sentaient pris au piège. Le dernier chapitre de la première partie est consacré à la réflexion que Césaire conduit autour de l'autobiographique dans la littérature, une modalité qui, selon lui, permet une interrogation de soi et du monde.

3 La deuxième partie de l'essai met en question l'œuvre des écrivains issus des anciennes colonies entre les années soixante et soixante-dix. La figure d'Édouard Glissant émerge dans ce contexte à côté de celle de Césaire. Malela consacre le premier chapitre à une 
vue d'ensemble des différentes idées et idéologies qui cohabitent dans le monde intellectuel de l'époque, afin d'en mettre en relief la complexité: phénoménologie, pensée marxiste, structuralisme, courant déconstructionniste sont autant de démarches philosophiques que les intellectuels plus jeunes décident ou non d'embrasser. Les représentants de la diaspora prennent, en général, le parti contestataire vis-à-vis de leurs prédécesseurs et tentent de se frayer un chemin qui leur appartienne totalement. Tout ce qui faisait partie du panorama précédent est remis en question, de nouvelles maisons d'édition et de nouvelles revues concurrencent celles qui avaient marqué l'histoire de la première décennie après la guerre. Glissant devient le nouveau maitre à penser de la colonialité et édifie, le premier, un discours philosophique et littéraire que Malela qualifie de postcolonial (p. 199). À travers l'analyse ponctuelle d'un corpus d'œuvres littéraires des principaux intellectuels africains et antillais (Glissant, Schwarz-Bart, Kourouma, Badian, Ouologuem, Dadié), l'auteur de l'essai met en relief l'approche glissantienne - que l'auteur définit avec le mot étètymalogique - qui servirait à ce dernier pour mettre en valeur le caractère complexe de la totalité dispersée, une perspective qui dépasse l'idée qu'il puisse y avoir un modèle unique, qui rassemble toutes les possibles variantes du réel. L'archétype de la parenté est ainsi analysé chez ces différents auteurs, tout comme le paradigme de la violence et de la souffrance. La problématique de la figuration de l'aliénation, de l'identité et de l'altérité chez les écrivains antillais fait l'objet du sixième chapitre qui met enfin l'accent sur le fait que les intellectuels antillais ont tous construit leur discours personnel à partir d'une critique explicite de la figure de Césaire qui se confirme ainsi, selon l'auteur, comme figuration de l'historicité antillaise et référence incontournable pour tout discours autour de l'identité diasporique. À travers une étude comparée de la pensée césairienne et glissantienne, Malela entend démontrer que si, du moins dans un premier temps, les résultats auxquels aboutissent les deux écrivains ne sont pas très différents, leur distinction s'effectue dans les moyens mobilisés. La relecture que fait cet essai de l'histoire des Afro-descendants à l'aune d'un esprit plus déconstructionniste et proximal, amène son auteur à s'interroger sur la colonialité du pouvoir aussi bien dans son versant racial que social. Son étude contribue à mieux faire connaître la réflexion de l'un des principaux penseurs de la colonialité et à la remettre en question, dans une perspective postcoloniale et postmoderne. 